\title{
Perspectivas dos atores ligados à vida acadêmica dos discentes em transição e adaptação escolar em assentamentos organizados pelo MST
}

\author{
Carmelo Souza da Silva ${ }^{1}$ \\ ${ }^{1}$ Faculdade Escritor Osman da Costa Lins - FACOL. Programa de Pós-Graduação em Pedagogia. Rua dos \\ Estudantes, Bairro Universitário, s/n. Vitória de Santo Antão - PE. Brasil. carmelosouza@ @otmail.com
}

RESUMO. Este artigo foi impulsionado pelo contexto histórico sobre a educação rural e a histórica luta dos movimentos campesinos por uma educação do campo, onde se investigou as compreensões, experiências e as expectativas dos atores ligados à vida acadêmica dos discentes do Ensino Fundamental em transição e adaptação escolar. Sendo assim, o objetivo desta pesquisa foi aprofundar a compreensão sobre o processo de transição e adaptação dos alunos das escolas rurais dos assentamentos do MST para as escolas públicas urbanas no Estado de Pernambuco. É uma pesquisa de natureza qualitativa com aportes quantitativos e para coleta dos dados optou-se pelos questionários, entrevistas e sonda cultural, junto aos alunos, professores, pedagogos, gestores das escolas, pais/responsáveis e líderes do MST. As informações aportadas nesse trabalho podem servir de conhecimento básico para gerar as discussões necessárias para a construção de projetos e amadurecimento de ideias que possam atender as singularidades da educação do campo e resultar em ações que possam resolver a questão das transições e adaptações escolares. Os resultados revelaram que as transições e adaptações escolares são sofridas e que há, desde uma possível acomodação, que pode até ser confundida com conivência, a limitações e falta de formação por parte dos atores responsáveis.

Palavras-chave: Movimentos Sociais, Educação do Campo, Transição, Adaptação Escolar. 


\title{
Perspectives of actors connected to the academic life of students in school transition and adjustment in settlements organized by the MST
}

\begin{abstract}
This article was driven by the historical context of rural education and the historic al struggle of farmer's movements for a rural education, where he investigated the understandings, experiences and expectations of the actors linked to the academic life of students of elementary school in transition and school adjustment. Thus, the aim of this research was to deepen the understanding of the process of transition and adaptation of students from rural schools the MST settlements to urban public schools in the state of Pernambuco. The qualitative and quantitative research and data collection was performed by questionnaires, interviews and school diaries with students, teachers, educators, managers of schools, parents / guardians and leaders of the MST. The collected information for this work allowed to generate basic knowledge to discussions needed for construction projects and maturation of ideas that can meet the singularities of the field of education, and result in actions that can address the issue of transitions and school adaptations. The results showed that the transitions and school adaptations are sustained and that there is, from a possible accommodation, which can even be confused with connivance, the limitations and lack of training for the responsible actors.
\end{abstract}

Keywords: Social Movements, Rural Education, Transition, School Adaptation. 


\section{Perspectivas de los actores vinculados a la vida académica de los estudiantes en transición y adaptación en escuela en asentamientos organizados por lo MST}

RESUMEN. Este artículo fue impulsado por el contexto histórico de la educación rural y la lucha histórica de los movimientos campesinos por una educación en el campo, dónde investigo las interpretaciones, experiencias y expectativas de los actores vinculados a la vida académica de los estudiantes de la escuela primaria en la transición y adaptación en la escuela. Por lo tanto, el objetivo de este trabajo fue profundizar en la comprensión Del proceso de transición y adaptación de los estudiantes de las escuelas rurales de los asentamientos del MST a las escuelas públicas urbanas en el estado de Pernambuco. La recolección de datos fue elegido por cuestionarios, entrevistas y sonda Cultural, con los maestros, educadores, directores de escuelas, padres/tutores y líderes del MST. La información aportadas pueden servir como base de conocimientos para generar debates necesarios para los proyectos de construcción y la maduración de las ideas que pueden satisfacerlas singularidades del campo de la educación, y dar lugar a acciones que puedan abordar el tema de las transiciones y adaptaciones escolares. Los resultados mostraron que en las transiciones y adaptaciones en las escuelas hay sufrimiento, compasibles limitaciones y falta de formación de los agentes responsables.

Palabras-clave: Movimientos Sociales, Educación Rural, Transición, Adaptación en la Escuela. 


\section{Introdução}

O contexto histórico sobre a educação rural e a histórica luta dos movimentos campesinos por uma educação do campo, em especificidade, as experiências pedagógicas em desenvolvimento do Movimento dos Trabalhadores Rurais Sem Terra - MST e seus múltiplos desafios para garantir a escolarização das crianças e adolescentes em escolas nos assentamentos, foi o que impulsionou o desenvolvimento dessa pesquisa.

As escolas instaladas nos assentamentos do MST têm como mantenedoras as prefeituras municipais de Vitória de Santo Antão, São Lourenço da Mata e Escada, onde estão localizados os assentamentos. Através da Secretaria Municipal de Educação, o governo municipal deve assistir e supervisionar as escolas que atendem àqueles assentados. São, na maioria das vezes, barracões ou salas construídas numa área chamada de espaço comum (onde ocorrem eventos e são praticadas atividades coletivas de interesse comum), local da sede da associação dos assentados, onde também é uma sala de aula que funciona no sistema multisseriado e lá a professora ou o professor tem o desafio de trabalhar com alunos do $1^{0}$ ao $5^{0}$ ano, que na maioria, são filhos de pais iletrados e filhos que estão fora da faixa etária nas séries que deveriam estar matriculados, ou seja, são alunos matriculados nas séries que não são compatíveis com as suas idades. Após o $5^{0}$ ano, esses alunos são transferidos para uma escola pública urbana para dar continuidade aos seus estudos.

Quanto às escolas públicas urbanas, percebe-se que muitas ainda estão longe de ser a escola ideal (bem equipadas e com professores bem preparados) para oferecer um ensino de melhor qualidade, principalmente àquelas escolas municipais e estaduais localizadas no interior do Estado. Muitas escolas possuem apenas a estrutura básica, ou seja, o mínimo para o seu funcionamento. $\mathrm{O}$ fato é que, embora o país esteja vivendo um momento de consenso quanto à questão da necessidade de mais investimentos para a educação, não se pode prever quando este consenso transformar-se-á, por exemplo, em infraestrutura que vá além dos itens básicos para o funcionamento de uma escola.

Dessa forma, é importante identificar junto aos atores das escolas envolvidas nessa pesquisa (professores, direção e pedagogos), lideranças do MST e pais ou responsáveis dos alunos, as suas compreensões e experiências referentes ao processo de transição e adaptação desses alunos. 


\section{Métodos}

A pesquisa realizada constitui-se de um estudo descritivo/exploratório, em que os fatos são observados, registrados, analisados, classificados e interpretados. Buscou-se pela clareza dos procedimentos técnicos e metodológicos, ou seja, a escolha de procedimentos sistemáticos para a descrição, interpretação e explicação dos fenômenos investigados ao longo do trabalho. Essa pesquisa tem uma abordagem metodológica qualitativa com aportes quantitativos. Com o método qualitativo procurou-se estabelecer conexões lógicas de causa e efeito entre os fenômenos, recorrendo a interpretações e utilizando alguns dados estatísticos. (Oliveira, 2003, p. 192).

Os atores entrevistados foram os professores (PROF), pais $(\mathrm{P})$ ou responsáveis (RESP), gestores (GEST), pedagogos (PED) e lideranças locais nos assentamentos do MST (L. MST), atores de grande importância na vida escolar e, consequentemente, de grande relevância para esta pesquisa.

Todos responderam a uma entrevista semiestruturada, com 04 (quatro) questões. As respostas obtidas dos citados autores foram tratadas estatisticamente, observando-se os discursos originais e aqueles agrupados por analogia e apresentados em quadros iniciados, a partir da enunciação de questões.

Os dados foram coletados em duas fases: a primeira, no último bimestre de 2010, quando os alunos ainda estavam cursando o $5^{\circ}$ ano do Ensino Fundamental, nas escolas localizadas nos assentamentos do MST (G1) e nas escolas urbanas (G2). Considerou-se a transição dos mesmos para uma nova fase escolar, ou seja, para o $6^{0}$ ano do Ensino Fundamental; na segunda fase a pesquisa concentrou-se nos atores envolvidos com os mesmos alunos (G1 e G2), ao longo do primeiro semestre de 2011, quando os alunos já se encontravam na nova fase escolar $\left(6^{0}\right.$ ano), no processo de adaptação.

As entrevistas, com os diretores ou responsáveis pelas unidades de ensino, professores que atuaram ou atuam diretamente com os alunos participantes desta investigação, os alunos participantes e os pais ou responsáveis por esses, foram previamente agendadas. A todos os participantes entrevistados pediu-se, individualmente, a autorização para gravação de voz. A entrevista foi semiestruturada, com perguntas abertas e gravadas para posterior transcrição, para não perder nenhuma informação que pudesse ocultar dados importantes. Por algum motivo, alguns participantes não autorizaram a gravação de voz, respeitando 
a recusa do entrevistado, limitando-se as anotações manuais.

Nessa pesquisa, as escolas de cada grupo (G1 e G2) estarão sendo representadas e identificadas por símbolos na forma de letras. O grupo G1: as escolas municipais localizadas nos três assentamentos do MST, localizados nas regiões da Mata Norte, Mata Centro e Mata Sul de Pernambuco (Escola do Assentamento A - EA-A); (Escola do
Assentamento B - EA-B) e a (Escola do Assentamento C - EA-C). O grupo G2: as Escolas Municipais localizadas na zona urbana, identificadas por Escola Urbana C - EUA; Escola Urbana D- EU-De a Escola Urbana F - EU-F.

\section{Análise e discussão dos dados Processo de transição escolar}

\section{a) As vésperas da ruptura}

Quadro 01 - Respostas dos pais (P) ou responsáveis (RESP) pelos alunos do G1: discursos originais e os envolvidos por analogia:

$1^{\text {a }}$ Questão: Já conversou alguma vez com seu filho sobre a mudança de escola e o processo de adaptação que o mesmo terá que passar na "nova escola"? O que foi falado?

\begin{tabular}{|c|c|c|c|}
\hline \multirow{2}{*}{ DISCURSO ORIGINAL } & \multirow{2}{*}{$\begin{array}{l}\text { SUJEITOS } \\
\text { ENVOLVIDOS POR } \\
\text { ANALOGIA }\end{array}$} & \multicolumn{2}{|l|}{ Total } \\
\hline & & $\mathbf{F}$ & \% aprox. \\
\hline $\begin{array}{l}\text { P3 - Já falei sim. Falei que vai ser mais } \\
\text { difícil e que terá que se esforçar mais. Lá } \\
\text { vai ser dureza, tem muitos professores e } \\
\text { muitas disciplinas. Não será como aqui, tem } \\
\text { mais alunos e a escola é muito grande. }\end{array}$ & $\begin{array}{l}\text { P2; RESP3; P4; P5; } \\
\text { RESP6; } \quad \text { RESP7; } \\
\text { RESP8; P9; RESP10; } \\
\text { P13; RESP15. }\end{array}$ & $11 / 15$ & $73 \%$ \\
\hline $\begin{array}{l}\text { P11 - Ela já conhece a escola, sempre vai lá } \\
\text { comigo quando sou chamado para reuniões } \\
\text { ou algo que o irmão dela faz de errado na } \\
\text { escola. O irmão dela estuda lá há dois anos. } \\
\text { Eu digo a ela que vai ser diferente da que } \\
\text { ela estuda agora. }\end{array}$ & P1; P11 e P12 & $3 / 15$ & $21 \%$ \\
\hline $\begin{array}{l}\text { P14 - Ele sabe onde fica. Eu já passei } \\
\text { várias vezes com ele pela escola e mostrei } \\
\text { onde ele vai estudar no próximo ano. } \\
\text { Sempre digo para ele que lá vai ser tudo } \\
\text { diferente. }\end{array}$ & P14 & $1 / 15$ & $6 \%$ \\
\hline
\end{tabular}

Fonte: Silva (2011) - Formatação do quadro adaptado de Bardin (1998).

As respostas oferecidas acima demonstram que a maioria dos pais ou responsáveis acreditam conhecerem a escola onde as suas crianças irão dar continuidade aos estudos no Ensino Fundamental apenas pelo fato de saber em 
que espaço geográfico a mesma está localizada. Pode-se verificar, ainda, que isto pode ocorrer, também, por entenderem que o fato de comparecerem à escola para participar de reuniões periódicas é suficiente para afirmar que a conhece na sua estrutura em funcionamento.

Segundo Morissawa (2008), existe uma cumplicidade muito importante entre escola e família nas áreas de acampamento e assentamentos. A escola para as crianças foi uma preocupação desde as primeiras ocupações do MST nas terras dos latifúndios. Foram pais, professores e estudantes que formaram as primeiras comissões para reivindicar e organizar escolas nos acampamentos e assentamentos. É nesse contexto que surgiu o Setor Nacional de Educação do MST. Portanto, entende-se não ser prudente e/ou justo vincular a falta de orientação dos alunos do G1, na sua transição à nova jornada escolar, a uma suposta falta de vontade ou desinteresse de apoio dos pais ou responsáveis.

\section{Quadro 02 - Respostas dos pais (P) ou responsáveis (RESP) pelos alunos do G2: discursos originais e os envolvidos por analogia:}

1ª Questão: Já conversou alguma vez com seu filho sobre as mudanças e o processo de adaptação que o mesmo terá que vivenciar na nova fase escolar? O que foi falado na oportunidade?

\begin{tabular}{|c|c|c|c|}
\hline DISCURSO ORIGINAL & SUJEITOS ENVOLVIDOS & \multicolumn{2}{|c|}{ Total } \\
\cline { 3 - 4 } & POR ANALOGIA & F & \% aprox. \\
\hline P23 - Sempre que nós estamos & P16; P17; P18; RESP19; P20; & $15 / 15$ & $100 \%$ \\
falando de escola eu lembro a ele & P22; P23; RESP24; RESP25; & & \\
que no próximo ano vai ser mais & RESP26; P27; P28; P29 e P30. & & \\
puxado... Digo para eles que a & & & \\
quantidade de professores e assuntos & & & \\
vai ser bem maior que nos outros & & & \\
anos passados... Que vai ter que & & & \\
estudar mais se quiser passar de ano. & & & \\
\hline
\end{tabular}

Fonte: Silva (2011) - Formatação do quadro adaptado de Bardin (1998).

As respostas acima revelam que os pais (P) e/ou responsáveis (RESP) pelos alunos do grupo G2 também são carentes de informações mais detalhadas sobre o funcionamento das escolas e, em particular, em relação à fase escolar do sexto ano a qual ingressarão seus filhos. Sendo assim, como consequência, esses pais e responsáveis demonstram não ter conhecimento para melhor prepararem seus filhos para uma transição escolar mais tranquila. Além disso, é comum, tanto nas periferias urbanas como nas comunidades rurais, onde é grande o número de pais e responsáveis analfabetos ou pouco escolarizados, responsabilizarem a escola na função de esclarecer os alunos acerca dessas transições. 
a) A escola: uma importante mediadora para uma transição sem sofrimento

Segundo os dados coletados nas entrevistas com as professoras das três escolas nos assentamentos do MST pesquisados, não existe uma preparação específica para a transição e adaptação escolar. Como se pode observar no discurso original de uma professora abaixo representado e que por analogia correspondem às opiniões das demais docentes:

Sou professora contratada da rede municipal de ensino e quando fui encaminhada para trabalhar nesta escola eu nem sabia que era uma escola onde estudavam os filhos dos assentados do MST. Eu achava que era uma escola rural como outra qualquer... Eu nunca fui chamada, nem pela Secretaria Municipal de Educação nem pela organização do MST para participar de alguma capacitação ou coisa parecida direcionada para essas questões de transferências, transições e adaptações dos alunos que encerram o $5^{\circ}$ ano e tem que se matricular numa escola lá na área urbana para continuarem seus estudos no $6^{\circ}$ ano do Ensino Fundamental (PROF G1do EA -B).

O discurso acima remete a outras discussões pertinentes e relevantes para a ilustração dos dados apresentados. Em primeiro lugar, como já é sabido, dificilmente um professor concursado e efetivo, já exercendo a sua docência em uma escola urbana, aceita ser transferido para trabalhar em uma escola rural a quilômetros de distância do centro urbano, salvo, se o docente for recém-concursado e não lhe restar outras opções. Normalmente as vagas para a docência nas escolas rurais são preenchidas por professores graduandos e não graduados, contratados temporariamente.

Quando as docentes foram questionadas se acreditavam que seus alunos do $5^{\circ}$ ano do Ensino Fundamental, sujeitos do G1, estavam sendo preparados suficientemente para ter uma transição e, posteriormente, uma adaptação escolar tranquila, responderam como pode ser conferido no discurso original abaixo apresentado e que por analogia representa as opiniões das demais, que não houve uma preparação específica e planejada pedagogicamente para tal fim.

Nas escolas da maioria dos assentamentos do MST, e é o caso desta aqui, a professora trabalha praticamente sozinha, não tem gestor, não tem pedagogo, não tem supervisor... Todas as orientações que são dadas para as professoras são passadas em reuniões na Secretaria Municipal de Educação... Eu desconheço se houve alguma orientação específica para se trabalhar com os alunos do $5^{\circ}$ ano estas questões sobre transição e adaptação escolar... Nós trabalhamos os conteúdos programáticos e sempre que possível nós falamos rapidamente sobre $o$ futuro escolar deles. (PROF - G1 da EA-A). 
Nas palavras da docente há um desabafo e ao mesmo tempo um reconhecimento de que os sujeitos do G1 não são preparados especificamente e pedagogicamente para as fases de transição e adaptação escolar. No entendimento das docentes a prioridade são os conteúdos programáticos.

Ao ser questionado como as lideranças locais dos assentamentos atuam em relação às escolas e o que é feito para oferecer uma transição e uma adaptação tranquila para aqueles alunos que tem que deixar a escola no assentamento para continuarem seus estudos numa escola num centro urbano, a resposta do líder, que por similitude representa as opiniões dos demais líderes entrevistados, foi a seguinte:

Eu sei que o MST possui um Setor de Educação que foi criado desde 1987 para tratar das questões do direito à educação e a escola das crianças... Eu não sei se ele cuida também dessa coisa de transição e adaptação... Eu sei que o MST acompanha os trabalhos de quase mil escolas do $1^{\circ}$ ao $9^{\circ}$ ano em quase todo país. Sei que o MST tem uma proposta pedagógica que defende um modelo de educação apropriado às demandas de um meio rural em transformação, que articule as experiências da realidade local com as experiências da realidade do mundo. (L do MST - Assentamento A).

Na fala do líder do MST, percebe-se que o mesmo não sabe se na escola localizada no assentamento, em que ele é presidente da Associação, há ou não uma preparação em relação à transição e adaptação para aqueles alunos que, compulsoriamente, estão deixando aquela escola onde estudaram todos os anos das séries iniciais e terão que passar para outra localizada na zona urbana, que apresenta uma proposta pedagógica diferente da sugerida pelo MST, que segundo Morigi (2003), esta propõe que a escola demandada deve ter uma identidade com o meio rural, seu currículo deve refletir essa identidade, assim como deve haver a criação de um ambiente educativo ao espaço onde se desenvolvam suas atividades.

No entendimento de Neto (1999), esse modelo de escola proposto pelo MST é a combinação da luta pela terra com a educação visando à construção de um "novo homem". (p. 57). O movimento compreende que a transformação da sociedade não pode se dar apenas através da ocupação de latifúndios. Contudo, diz ainda o autor, para a construção do "homem novo" de quem falam os membros do MST, só será possível a partir de uma reeducação para a vida no coletivo, com uma formação diferenciada, sem os vícios do sistema capitalista.

\section{Semelhanças e diferenças nas adaptações nos diferentes contextos}




\section{a) Conviver com o diferente: desconforto, estranheza, ansiedade e angústia}

Embora sejam os alunos do G2 acostumados a frequentarem a mesma escola há alguns anos, não ficaram imunes ao medo ou ao nervosismo do primeiro dia de aula.

O que aparece como diferencial em relação aos alunos do G1, talvez sejam as poucas queixas, ou seja, quando eles falam de medo e nervosismo não oferecem detalhes de como esses se manifestaram. Eles falam de nervosismo e de medo como algo que lhes apareceram tão rápido quanto desapareceram. Não que essas condições que os diferenciam sejam méritos incontestáveis da escola e da família, pois já ficou demonstrado nesta pesquisa que não houve preparação planejada e sistemática.

A propósito, quando se perguntou aos pais ou responsáveis pelos alunos dos dois grupos (G1 e G2) se o filho ou filha reclamava de alguma dificuldade ou sentimentos na etapa de adaptação, no início da nova fase escolar, quais as reclamações e quais as orientações passadas às crianças, pelos pais ou responsáveis, as respostas foram simples e revelaram que estes não estavam preparados e nem sabiam como lidar conscientemente com a situação.

\section{Reflexos da ruptura no desempenho acadêmico}

\section{a) Assiduidade, evasão e desempenho escolar}

As dificuldades para o deslocamento entre as áreas rurais e urbanas, principalmente em tempo de chuva, não caracteriza nenhuma novidade. $\mathrm{O}$ fato relevante a ser discutido nesta pesquisa são as consequências dessa realidade na vida acadêmica dos sujeitos desta investigação, que inclusive correm o risco de perder o ano letivo, já que, quando o aluno deixa de frequentar a escola, não atendendo a exigência mínima de $75 \%$ de frequência, de acordo com o artigo 24 - VI da LDB (Lei $n^{\circ}$ 9394/96), fica caracterizado o abandono escolar. Além dos prejuízos ou perdas no processo de ensino e aprendizagem, existe ainda a questão do desestímulo diante dos desafios para os quais os alunos não veem uma solução, pelo menos em curto prazo.

Ao entrevistar as professoras nos três assentamentos do MST houve importantes revelações. As docentes, quando responderam a questão a qual perguntava quais os maiores desafios que os seus alunos iriam enfrentar na nova fase escolar, entre outras coisas, falaram sobre assiduidade e fizeram algumas previsões sobre alguns desafios que deveriam passar os alunos do G1. Afirmaram com muita 
convicção que os discentes perderiam algumas aulas em razão do transporte não conseguir chegar até o assentamento, por causa das condições das estradas agravadas pelas chuvas. (PROF da EA- C-G1).

As professoras estavam seguras de que os alunos, sujeitos do grupo G1, perderão muitas aulas por causa das condições que elas já vivenciam há algum tempo. Elas sabem, assim como os pais, as autoridades e a sociedade, que quando as crianças chegam atrasadas na escola ou perdem um dia de aula, há um prejuízo real. O aluno pode até conseguir com os colegas os assuntos escritos, pedindo um caderno emprestado ou o número das páginas do livro trabalhadas na aula, no entanto, ele perdeu a explicação do professor ou professora. É a esse prejuízo que se refere à professora no seu discurso.

De acordo com Vendramini (2000), "as dificuldades das professoras que vem das cidades para as escolas rurais, sofrem com as difíceis condições das estradas, bem como com a distância e as péssimas condições dos transportes”. (p. 185). Ele está retratando, mesmo indiretamente, exatamente os mesmos desafios que os jovens estudantes enfrentam no dia a dia para dar continuidade aos seus estudos na área urbana.

Corrobora para essa discussão o pensamento de Moreira (2007, p. 82-106) quando diz "se o cidadão está obrigado a matricular seu filho, o Estado está obrigado não somente a disponibilizar vagas. A educação não deve ser focada no aspecto quantitativo, mas também no aspecto qualitativo". No entendimento do autor não é suficiente dizer que os sujeitos têm escola para frequentar, se a eles não for oferecido às condições necessárias para o acesso naquela escola. Como por exemplo, transporte decente e estradas seguras.

\section{Desafios políticos pedagógicos do MST}

Para se chegar a uma ideia temática que possibilitasse a formação desta Categoria com sua Unidade de Análise, foram priorizadas as respostas ou discursos coletados de algumas lideranças do MST, nos três assentamentos onde se encontram as três escolas rurais. $\mathrm{A}$ análise $\mathrm{e}$ as discussões dos resultados deram-se a partir de algumas literaturas mais específicas sobre os princípios filosóficos e pedagógicos da educação no MST.

\section{a) Uma formação na contramarcha da ideologia do movimento}

Esta Unidade de Análise tem seu início a partir de um questionamento feito aos líderes (Presidentes de Associações e Coordenadores do MST) nos três assentamentos onde se deu a pesquisa. Foi perguntado aos líderes (uma mulher e dois homens) se existe, na política pedagógica 
do MST, alguma preocupação específica para a questão da transição e adaptação daqueles alunos que estão tendo de deixar as escolas públicas nos assentamentos para poder dar continuidade aos seus estudos no Ensino Fundamental II, numa escola pública na área urbana.

Como resposta, obteve-se dos três líderes o que se pode conferir nos discursos originais abaixo representados:

\section{Primeiro discurso:}

O que eu sei é que o movimento tem se preocupado bastante com o futuro dessas crianças e adolescentes... Para o MST conquistar educação pública e de qualidade para todos os níveis é tão importante quanto à conquista da terra. A orientação pedagógica do Movimento é passada para nós (liderança comunitária, professoras, professores, delegados de ensino, etc.). Embora, é importante lembrar, que para tudo funcionar direitinho, conforme a orientação pedagógica dada pelo Setor de Educação do Movimento carece do comprometimento de todos. Essa luta teve início nos anos 80, quando o MST criou as frentes ou setores articulados e um deles foi o Setor de Educação... Assim o Movimento foi amadurecendo no dia-a-dia, na prática e com as necessidades... Foi assim que se percebeu que os filhos dos acampados e dos assentados precisavam de escola, que não poderia continuar os pais aflitos porque os filhos estavam sem poder ir à escola, que ficava na cidade a quilômetros do lugar que estavam. Muitos acampados queriam desistir do acampamento por conta desta situação... Foi aí que nasceu a ideia de criar as escolas nos barracões... As experiências acumuladas vão oferecer as condições para a construção de um Projeto Político
Pedagógico - PPP do MST. Eu sei que o PPP do MST tem defendido uma educação além da escola, uma formação humana com uma visão globalizada... Mas não posso assegurar que exista neste Projeto, essa preocupação específica que o senhor me pergunta. Penso que a professora e a família dos alunos devem trabalhar essa preparação. (L. MST - Assentamento - A).

No primeiro discurso se percebe que a líder reafirma o que já vem sendo dito nas literaturas produzidas pelo MST sobre a luta do Movimento para conquistar escola pública de qualidade para toda a população do campo. Ela diz que orientações pedagógicas são passadas para as lideranças comunitárias, docentes e delegado de ensino, mas acredita que toda orientação só será praticada com eficácia se houver um comprometimento das partes interessadas envolvidas. Ela disse que não tinha como assegurar que existia no Projeto Político Pedagógico do MST uma preocupação específica com relação à questão de transição e adaptação de alunos que vão para outra escola. Mas a líder diz ainda, acreditar que os professores e as famílias dos alunos em transição devem estar fazendo este trabalho. Ela lembra que o MST tem feito um trabalho intenso de conscientização da necessidade da participação de todos da comunidade interessados na gestão escolar, para se alcançar os objetivos propostos. (L. MST Assentamento - A). 
Neste sentido, segundo Neto (1999), “a orientação pedagógica dada pelo Setor de Educação do MST aos professores e às lideranças comunitárias é estimular a iniciativa de construção de conteúdos e metodologias de ensino mais próximos e adequados ao contexto econômico e sociocultural dos assentamentos". (p. 52). Essa situação sinaliza para outras possibilidades, como por exemplo, pode-se acreditar que há liberdade para a inclusão de novos desafios nos Projetos e nas práticas pedagógicas do Movimento, como a preparação dos alunos para uma transição tranquila.

Contudo, o primeiro discurso nem afirma haver na Política Pedagógica do MST alguma preocupação específica em relação às questões de transição e adaptação escolar, nem nega a existência de ações pedagógicas voltadas para tais fins.

\section{Segundo discurso:}

Há décadas o MST vem defendendo escolas públicas de qualidade para todos no campo, para não ter que ver as crianças $\mathrm{e}$ os adolescentes se deslocarem a quilômetros de distância para estudar numa escola na zona urbana, para receberem uma formação conservadora, do ponto de vista político e ideológico, que não tem nenhum compromisso com o homem do campo, que só contribui para o êxodo rural... Quanto à questão da transição e adaptação dos alunos, é possível que se tenha essa preocupação inclusa, de forma contextualizada nos princípios pedagógicos, onde se procura colocar em prática os princípios filosóficos da educação, numa visão de mundo, de formação de sujeitos como pessoa e como sociedade... Eu não sei dizer com certeza, se na prática está sendo trabalhada, de forma planejada e específica essa questão da transição e adaptação... Sinceramente, eu ainda não tinha despertado para essa situação, que é realmente muito importante. (L

Assentamento - B).

No segundo discurso, após lembrar que o MST vem lutando por escolas públicas de qualidade, paralelamente as suas militâncias pela reforma agrária, o líder critica $o$ fato das crianças e adolescentes terem que passar pelo sacrifício e sofrimento do deslocamento de quilômetros de distância para receberem uma formação que, segundo ele, é conservadora e que não contribui para a fixação do homem no campo. $\mathrm{Na}$ sequência ele afirma que é possível haver alguma preocupação nos princípios pedagógicos do MST com relação às questões das transições e adaptações dos alunos, embora não saiba dizer se na prática estão sendo trabalhadas. Por final, o entrevistado assumiu que ainda não tinha despertado para as questões da transição e adaptação dos alunos e reconheceu a importância da preocupação e discussão do fato.

Afirma ainda o entrevistado, que o MST tem uma proposta de educação 
ampla, com uma visão larga de mundo, que visa preparar o aluno para ser capaz de intervir e transformar práticas na realidade que vive. Percebe-se que o mesmo o faz com base nos princípios filosóficos do Movimento, que se encontra no Caderno de Educação $n^{\circ}$ 8. Presume-se que ele conhece bem a proposta teórica. O modelo de escola proposto pelo MST diz-se ser comprometido com uma formação que parte de uma realidade concreta. Segundo Freire (2005), na prática, seria uma escola onde o aluno não seria um sujeito coadjuvante e, sim, parte ativa da construção da história de seu país e da humanidade.

Para Silva (2010), esta escola seria o local onde a comunidade escolar vivenciaria ações compartilhadas numa visão, onde promoveriam críticas aos valores e conceitos que estivessem prejudicando a ação histórica daquela sociedade. Seria o lugar onde estaria sendo construída, de forma progressiva a contra ideologia, que seria uma forma de superação da ideologia dominante.

Quando em entrevista dada à Carta Capital, o líder ideológico nacional do Movimento, João Pedro Stedile, considerado pelos ruralistas brasileiros e parte da imprensa nacional como "reencarnação da besta-fera", falou, entre outros assuntos, de transitoriedade.
Segundo Lírio (2009), para Stedile, não importa governo ou sistema econômico, se conseguirmos formar uma geração mais instruída ela conseguirá encontrar as melhores soluções para os problemas sociais.

É importante frisar que o Movimento defende, no seu modelo de formação, a necessidade de respeitar a transitoriedade, permitindo o entendimento de que o MST está disposto a encarar novos desafios. Segundo a literatura do MST, quando o Movimento fala de uma educação aberta para o mundo, está justificando para insistir numa proposta de educação própria. Não significa dizer que o movimento se feche nos limites da sua realidade imediata ou das suas lutas específicas (MST, 1996). Tais condições comprometeriam os objetivos maiores de mudanças do Movimento.

Contudo, é relevante lembrar, no que concerne à teoria e a prática do MST em relação à educação que, segundo Alves (2009), “os principais porta-vozes do movimento anunciam sistematicamente uma concepção de educação e uma prática pedagógica que estariam bem distantes daquelas realizadas nas escolas estatais e privadas, mas que a retórica esconde o exercício da mesmice". (p. 11). O que seria equivalente dizer que a proposta de educação do MST não iria além da 
superfície do discurso e que não há diferença qualitativa.

\section{Terceiro discurso:}

Algo específico assim acho que não. A professora deve fazer alguma preparação no final do ano para eles... Pensando direitinho, essa situação de mudança de escola, ter que se adaptar com tudo diferente novamente é uma situação difícil... Essa situação pode ser 'aquilo' que o Setor de Educação chama de novas dimensões ou novas experiências no processo de formação humana... É normal a cada tempo surgir uma nova necessidade, que deve ser discutida no coletivo e em seguida procura-se colocar na prática as novas exigências. $\mathrm{O}$ maior desafio para $\mathrm{O}$ MST não é pensar filosoficamente e pedagogicamente essa situação que o senhor colocou ai, sobre transição e adaptação dos alunos para outra escola, desafio mesmo é transformar as ações pensadas em práticas... A prática depende da conscientização e participação de todos. O MST espera que todas as ações sejam executadas com a consciência da necessidade e o sentimento do prazer do coletivo... Entendemos que a força de um companheiro vai estar na força da organicidade do coletivo e que o contrário também é verdadeiro. (L. MST - Assentamento - C).

No terceiro discurso, o líder entrevistado foi apenas um pouco mais direto. Ele diz achar que algo específico, na política pedagógica do MST voltado para as questões de transição e adaptação de alunos, não existe. Em seguida, ele ameniza dizendo que acreditava que as professoras faziam alguma preparação no final do ano letivo para os alunos que mudavam de escola. Posteriormente, o líder também reconheceu a importância do assunto questionado e "profetizou" dizendo que será um novo desafio para o MST. Neste momento, acontece o que se pode dizer um reconhecimento, por parte do líder, que não há no Projeto Pedagógico do MST (nem na prática planejada nem no currículo oculto) uma preocupação específica com relação à transição e adaptação dos alunos transferidos das escolas públicas no assentamento para as escolas públicas urbanas.

\section{Considerações finais}

Devemos destacar que os referidos principais atores envolvidos na vida escolar dos alunos (G1 e G2), não estão preparados para lidar com as questões relacionadas à transição e adaptação dos discentes na sua nova fase escolar.

Em relação aos pais ou responsáveis, quando perguntados às vésperas da transição escolar, se já haviam conversado alguma vez com seu filho sobre a mudança de escola e o processo de adaptação, responderam que sim. Mas, os mesmos só falaram para seus filhos que na outra escola seria mais difícil, que haveria mais professores e mais matérias, nenhuma informação planejada e sistematizada pedagogicamente, voltadas à preparação para uma transição e adaptação tranquila para as suas crianças, foram passadas. 
Tanto os pais ou responsáveis do G1 como o do G2 acreditam que informar os filhos que na próxima fase escolar será mais difícil, é estar preparando-os para uma transição tranquila. São unânimes em informar que nunca foram convidados para participar de alguma reunião para tratar da questão da transição e adaptação das suas crianças à nova fase escolar. Portanto, se esses pais ou responsáveis não foram preparados, não se pode esperar que os mesmos tenham conhecimentos para preparar seus filhos, a fim de obter uma transição e uma adaptação tranquila.

Constatamos que não só os alunos, como também os pais dos dois grupos (G1 e G2), são carentes de informações mais detalhadas sobre o funcionamento das escolas, bem como acerca da fase escolar (sexto ano) em que suas crianças estarão indo estudar. Além disso, é importante frisar que é comum, tanto na zona rural quanto nas periferias das zonas urbanas, haver um grande número de pais ou responsáveis analfabetos ou com pouca escolaridade.

A propósito, espera-se que toda família esteja preparada para dar o suporte necessário a seus filhos, para que os mesmos possam atender as expectativas da escola e do mundo do trabalho. Mas, essa tarefa pode não ser fácil, porque vai depender de outros fatores como situação econômica, estrutura familiar, nível de formação e disponibilidade. Esse quadro se torna mais visível no caso das famílias economicamente desfavorecidas nas periferias urbanas e na área rural.

Contudo, a situação acima retratada vai mais além dessas questões, de ter ou não conhecimento e interesse de prepararem os alunos para a transição, pois a questão é falta de formação e informação. Não existe formação de professores, gestores para lidar com a situação, nos dois contextos investigados. Nem as escolas que estão enviando os alunos (escolas públicas nos assentamentos), nem as escolas que estão recebendo os alunos (escolas públicas urbanas), e nem essa segunda escola quando também faz o processo de envio e recebimento interno de seus alunos do $5^{\circ}$ ano para o $6^{\circ}$ ano do Ensino Fundamental, não possuem ações planejadas que visem à transição e a adaptação dos alunos. Os pais não estão sendo orientados a gerenciar a rotina dos seus filhos. Essas escolas que estão recebendo os novos alunos, independentemente de onde vierem, não os oferecem uma recepção mais atenta e especial, o que iria contribuir significativamente para uma melhor qualidade no convívio social-escolar.

Outra situação relevante, que contribui com as considerações finais 
acima apresentadas, é o fato das professoras das escolas pesquisadas nos assentamentos do MST não serem efetivas e de não serem graduadas, ou ainda não terem concluído a graduação. Como elas são contratadas temporariamente, consequentemente, há uma rotatividade muito grande dessas professoras nas escolas rurais, o que compromete a continuidade dos trabalhos docentes. Algumas dessas professoras informaram que foram enviadas para trabalhar numa escola rural, mas que ninguém lhes disse que se tratava de uma escola num assentamento do MST, que nunca foram chamadas, nem pela Secretaria Municipal de Educação e nem pelo MST para participar de alguma capacitação ou algo parecido para tratar da questão da transição e adaptação dos alunos que são transferidos para as escolas públicas na cidade.

Outra questão que merece ser destacada é o fato dos líderes locais dos assentamentos do MST não saberem com segurança se o Setor de Educação do Movimento e as escolas nos assentamentos tratavam ou não da questão da preparação dos alunos para uma transição e adaptação tranquila a uma nova escola. Apesar de demonstrarem ter muito conhecimento sobre os princípios filosóficos e pedagógicos do MST, eles só conseguiram afirmar que "achavam que a escola, as professoras e os pais estavam tratando da questão", ideias contrariadas pelos resultados dessa pesquisa.

Nesta fase, com base nos discursos dos sujeitos do G1, de seus pais ou responsáveis e de algumas lideranças do MST dos três assentamentos, além de estarmos atentos às literaturas produzidas dentro do próprio movimento, que trazem os princípios filosóficos e pedagógicos da educação no MST, chegou-se à conclusão que, embora o Movimento tenha uma política pedagógica bem clara e definida, essa não traz nenhuma proposta específica para lidar com a realidade da transição e adaptação dos alunos que saem das escolas públicas nos assentamentos para estudar nas escolas públicas urbanas.

Todas as informações coletadas com os sujeitos do G1, pais e responsáveis e lideranças, convergiram para a confirmação de que não existe nada planejado ou alguma ação prática sistematizada com relação à preparação dos alunos em processo de transição e adaptação escolar. Mas, também é fato confirmado que no MST, que tem seus princípios filosóficos pedagógicos numa construção permanente, sempre vai haver espaço para novos desafios. O que não deixa de ser uma sinalização positiva e alimentadora de esperanças. 
É relevante destacar que os alunos, nos assentamentos pesquisados, não estão apenas desassistidos no que diz respeito à preparação para a transição e adaptação escolar, como também não há por parte de seus familiares um diálogo mais presente sobre o que significa o MST e qual o significado da Reforma Agrária. O que significa que estão deixando de receber a formação que para o Movimento é fundamental, já que sua proposta é a formação de uma militância permanente, comprometida com o desenvolvimento de uma consciência de classe e uma consciência revolucionária. $\mathrm{O}$ que se constata é uma situação onde a formação dessas crianças está seguindo na contramarcha da ideologia do MST. O futuro do MST, que está sendo desenhado hoje, deixa dúvidas, pois a prática perece e pode estar condenando-o à extinção.

Os resultados dessa investigação revelaram situações negativas que ocorrem no cotidiano de escolas públicas rurais e urbanas no Estado de Pernambuco. Situações que parecem invisíveis aos olhos da sociedade e, principalmente, aos olhos daqueles que são coautores e responsáveis, os que não deveriam permitir que tais situações, como desconforto e sofrimento aos discentes nas transições e adaptações escolares, ocorressem.
A percepção que se tem é que há, desde uma possível acomodação, que pode até ser confundida com conivência, a limitações e falta de formação por parte dos atores responsáveis por realizar, proteger, respeitar e garantir o direito a educação básica de qualidade e sem discriminação a todas as crianças do campo e da cidade.

Embora essa pesquisa tenha sido realizada em apenas três escolas nos assentamentos do MST e três escolas na zona urbana, localizadas em três cidades do Estado de Pernambuco (Vitória de Santo Antão, São Lourenço da Mata e Escada), ofereceu-se uma amostra relevante de uma realidade que pode ser a mesma dentro de um universo maior de cidades no Estado e no País, mas que pode ser revertida. As informações aportadas nesse trabalho investigativo podem servir de conhecimento básico para gerar as discussões necessárias para a construção de projetos e amadurecimento de ideias que possam atender as singularidades da educação do campo, como defende o MST, e resultar em ações que possam resolver a questão das transições e adaptações escolares. Mas, assim como nas escolas urbanas, nas escolas nos assentamentos, as soluções dependerão, principalmente, da força organizativa e do comprometimento 
de todos, além da importância de que as crianças não deixem de ser ouvidas.

\section{Referências}

Alves, G. L. (Org.). (2009). Educação no campo: recortes no tempo e no espaço. Campinas, São Paulo: Autores Associados.

Bardin, L. (1988). Análise de conteúdo. Lisboa, Portugal: Edições70.

Lei 9.394, de 20 de dezembro de 1996. (2001). Estabelece as diretrizes e bases da educação nacional e legislação correlate. Brasília: Câmara dos Deputados; Coordenação de publicações. Legislação, n. 38 .

Freire, P. (2005). Pedagogia do oprimido. Rio de Janeiro: Paz e Terra.

Lirio, S. (2009). Especial 25 anos depois. Carta Capital, 55(530), p. 8-15.

MST. (1996). Princípio da educação no MST. São Paulo: Setor de Educação (Caderno de Educação $\mathrm{n}^{0} 8$ ).

Moreira, O. R. (2007). Políticas públicas e direito à educação. Belo Horizonte: Fórum.

Morigi, V. (2003). Escola do MST: uma utopia em construção. Porto Alegre: Mediação.

Morissawa, M. (2008). A história da luta pela terra e o MST. São Paulo: Expressão Popular.

Neto. L. B. (1999). Aprende e ensina: estudo sobre as práticas educativas do movimento dos trabalhadores rurais. Campinas: São Paulo: Autores Associados. dissertações e teses. Recife: Edições Bagaço.

Silva, C. S. (2010). Gramsci: Uma educação para a formação de uma sociedade alternativa participativa. Revista Conexão Pedagógica, 3(3), 9-25. . (2014). Escuelas públicas del Movimiento de los Trabajadores Rurales Sin Terra y urbanas: el impacto de la transición y adaptación de los alunos em enseñanza fundamental, em el Estado de Pernambuco, em los años de 2010 y 2011. (Tese de Doutorado). Universidad De La Empresa.

Vendramini, C. R. (2000). Terra, trabalho e educação: experiências sócioeducativas em assentamentos do MST. Ijeú: Editora Unijuí.

Recebido em: 06/11/2016 Aprovado em: 14/03/2017 Publicado em: 19/04/2017

Como citar este artigo / How to cite this article / Como citar este artículo:

APA:

Silva, C. S. (2017). Perspectivas dos atores ligados à vida acadêmica dos discentes em transição e adaptação escolar em assentamentos organizados pelo MST. Rev. Bras. Educ. Camp., 2(1), 345-363. DOI: http://dx.doi.org/10.20873/uft.2525$\underline{4863.2017 \mathrm{v} 2 \mathrm{n} 1 \mathrm{p} 345}$

\section{ABNT:}

SILVA, C. S. Perspectivas dos atores ligados à vida acadêmica dos discentes em transição e adaptação escolar em assentamentos organizados pelo MST. Rev. Bras. Educ. Camp., Tocantinópolis, v. 2, n. 1, p. 345-363, $2017 . \quad$ DOI: http://dx.doi.org/10.20873/uft.2525$\underline{4863.2017 \mathrm{v} 2 \mathrm{n} 1 \mathrm{p} 345}$

Oliveira, M. M. (2003). Como fazer projetos, relatórios, monografias, 